\title{
EL CORPUS MEDIEVAL DE LA LÍRICA POPULAR CATALANA CON VOZ FEMENINA*
}

\author{
Rafael M. MÉRIDA JIMÉNEZ \\ rmmerida@filcef.udl.es \\ Universitat de Lleida
}

\section{Contextos CRíticos}

A lo largo de la segunda mitad del siglo $\mathrm{xx}$, las investigaciones dedicadas a la cultura literaria en la Europa medieval han ido recuperando y vindicando el legado de nuestras antepasadas, escasamente valorado hasta entonces. En especial desde las disciplinas historiográficas y filológicas, el estudio sobre las mujeres de aquellas centurias ha ido ampliando nuestro conocimiento y ha favorecido el desarrollo de nuevas aproximaciones que han enriquecido los modelos interpretativos para una mejor comprensión de la multiplicidad de papeles que interpretaban. En la actualidad, podemos afirmar que sabemos mucho más de ellas que hace relativamente poco tiempo, sobre sus actividades y representaciones, sobre los espacios sociales y políticos que ocupaban o sobre su creatividad, según demuestra implícitamente, por ejemplo, un repertorio bibliográfico en torno al espacio ibérico medieval ${ }^{1}$. A nadie debe sorprender que haya sido desde perspectivas directa o indirectamente inspiradas por el feminismo que más se haya trabajado para explorar este territorio menospreciado por cierta crítica; Alan Deyermond casi iniciaba su ponencia para el congreso de la Asociación Hispánica de Literatura Medieval celebrado en Granada (1993) afirmando:

Hace poco más de veinte años pareció excéntrico, hasta perverso, el dedicar un espacio mínimo a las autoras medievales castellanas: Antonio Antelo, reseñando la edición inglesa de mi historia de la literatura medieval, se quejó del espacio concedido a dichas autoras, cuando se podría dedicar a un estudio más amplio de autores realmente importantes (todos masculinos, desde luego) ${ }^{2}$.

\footnotetext{
* Este trabajo forma parte del proyecto FEM2015-69863-P MINECO-FEDER.

${ }^{1}$ Rafael M. Mérida Jiménez, Mujer y cultura literaria en las letras ibéricas medievales y del Renacimiento temprano, Kassel, Reichenberger, 2011.

${ }^{2}$ «Las autoras medievales castellanas a la luz de las últimas investigaciones», en J. Paredes (ed.), Medioevo y Literatura. Actas del V Congreso de la Asociación Hispánica de Literatura Medieval, Granada, Universidad de Granada, 1995, vol. 1, pp. 31-32.
} 
Como no podía ser de otra manera, en el caso de la tradición literaria, las investigaciones han sido múltiples: en primer lugar, se han editado o reeditado numerosos textos, en verso y en prosa, escritos por mujeres con el triple objetivo de recuperar sus creaciones, de averiguar sus significaciones y de reformular su puesto en la sociedad para valorar mejor cada literatura y sus interrelaciones. De esta manera, han podido proponerse nuevas genealogías, así como revisarse las fuentes comunes y las corrientes que inspiraron o configuraron la escritura femenina durante un período de tiempo tan dilatado en una Europa multilingüe como fue aquella. En segundo lugar, las investigaciones han ido interesándose por los diversos contextos que generaron la cultura letrada en la cual participaron las mujeres: desde el aprendizaje de la lectura o de la escritura hasta su formación intelectual, pasando por los espacios que mejor la favorecieron, la transmisión de sus saberes (espirituales, técnicos, científicos, ...) o las dimensiones de su mecenazgo en las cortes y en las ciudades. La labor no ha sido minúscula, sobre todo si tenemos en cuenta, además, la diversidad de los posibles acechos y la interdisciplinariedad que puede llegar a exigir este tipo de investigación.

La lírica femenina europea en lengua vulgar ha sido un territorio revisado con frecuencia por este motivo, destacando las aportaciones en torno a las trobairitz en lengua occitana, las chansons de femme francesas o los frauenlied germánicos, entre otros ${ }^{3}$. En el ámbito de los estudios literarios hispánicos, no cabe duda de que las aportaciones de Alan Deyermond deben considerarse de enorme trascendencia, empezando por su cuidadosa y dilatada reevaluación de los testimonios conservados ${ }^{4}$; en lo que atañe a la lírica «popular» castellana, objetivo de estas páginas, las ediciones y los análisis de Margit Frenk constituyeron un hito de indudable importancia por su envergadura ${ }^{5}$,

\footnotetext{
${ }^{3}$ Véanse, a modo de ejemplo, Angelica Rieger (ed.), Trobairitz: Der Beitrag der Frau in der altokzitanischen höfischen Lyrik, Tübingen, Niemeyer, 1991; Pierre Bec (ed.), Chants d'amour des femmes-troubadours. Trobairitz et «chansons de femme», Paris, Stock, 1995; Anne L. Klinck y Ann Marie Rasmussen (ed.), Medieval Woman's Song. Cross-Cultural Approaches, Philadelphia, University of Pennsylvania, 2002, y María Paz Muñoz y Juan Carlos Búa (eds.), Lírica medieval alemana con voz femenina (siglos XII-XIII), Valladolid, Universidad de Valladolid, 2007. Por supuesto, no deben olvidarse estudios tan clásicos como los de Peter Dronke, Women Writers of the Middle Ages, Cambridge, Cambridge University Press, 1984, y Vicenç Beltran, La poesía tradicional medieval y renacentista. Poética antropológica de la lírica oral, Kassel, Reichenberger, 2009.

${ }^{4}$ Solo citaré dos de los trabajos de Deyermond que constituyen piezas indispensables: «Sexual Initiation in the Woman's-Voice Court Lyric», en K. Busby y E. Kooper (eds.), Courtly Literature. Culture and Context, Amsterdam-Philadelphia, John Benjamins, 1990, pp. 125-158, y «Lust in Babel: Bilingual Man-Woman Dialogues in the Medieval Lyric», en A. Menéndez Collera y V. Roncero Mayor (eds.), «Nunca fue pena mayor». Estudios de literatura española en homenaje a Brian Dutton, Cuenca, Universidad de Castilla-La Mancha, 1996, pp. 199-221.

${ }^{5}$ Además de la edición del Nuevo corpus de la antigua lírica popular hispánica (siglos XV a XVII), México, Fondo de Cultura Económica, 2003, recordemos su Poesía popular hispánica: 44 estudios, México, Fondo de Cultura Económica, 2006.
} 
junto a las investigaciones de Pilar Lorenzo Gradín $n^{6}$. Sin embargo, debe afirmarse que la poesía femenina -o con dicha voz lírica- en lengua catalana apenas ha merecido atención crítica, como sugiere el hecho de que la mayoría de las antologías de fuentes primarias o las misceláneas de estudios de ámbito europeo, e incluso estrictamente ibérico, apenas la editen o citen ${ }^{7}$, a diferencia de la presencia más habitual de testimonios castellanos y gallego-portugueses: una de la escasas excepciones sería el florilegio de Aguadé i Benet ${ }^{8}$.

Los testimonios conservados de la producción poética femenina en lengua catalana durante el otoño medieval son escasos ${ }^{9}$. De autoría reconocida serían «Ez yeu am tal que`s bo e belh» (de la primera mitad del siglo XIV), atribuido a «La Reina de Mallorques», cuya identidad aún se discute -¿Constança d'Aragó o Violant de Vilaragut?-, y los versos de Tecla Borja (1435-1459) que han sobrevivido en un poema dialogado de Ausiàs March: «Entre-1s ulls y les orelles». El resto de piezas que la crítica ha valorado hasta la fecha son anónimas: serían los casos de «Lassa, mays m'agra valgut» (quizá de la primera mitad del siglo XIV), «Axí cant és en muntanya deserta» (de finales del XIV), y «Ab lo cor trist envirollat d'esmai» (de finales del XIV). En lo que atañe a la tradición popular los textos apenas superan la veintena. Si quisiéramos comparar este legado con el de otras áreas poéticas íbero-románicas, constataríamos que la lírica femenina castellana cuenta con un volumen superior de versos y de autoras -Mayor Arias, María Sarmiento, Catalina Manrique, Marina Manuel o, la más importante de todas ellas: Florencia Pinar ${ }^{10}-$ y que, en el área gallego-portuguesa, el subgénero conocido como cantiga d'amigo ofrece un indispensable corpus de versos con voz femenina, aunque adjudicados a poetas varones en los manuscritos que los conservan ${ }^{11}$; además, conviene recuperar muchos versos de damas

\footnotetext{
${ }^{6}$ Así el pionero La canción de mujer en la lírica medieval, Santiago de Compostela, Universidade de Santiago de Compostela, 1990.

${ }^{7}$ Serían los casos de Doris Earnshaw, The Female Voice in Medieval Romace Lyric, New York, Peter Lang, 1988; Anne L. Klinck (ed.), An Anthology of Ancient and Medieval Woman's Song, New York, Palgrave Macmillan, 2004; o Danielle Régnier-Bohler (ed.), Voix de femmes au Moyen Âge, Paris, Robert Laffont, 2006.

${ }^{8}$ Rosamaria Aguadé i Benet (ed.), La veu de la dona a l'Edat Mitjana, Castelló d'Empúries, Ajuntament, 1994, pp. 101-114.

${ }_{9}^{9}$ Véanse las siguientes entradas de Lola Badia: «Anonymous Catalan Medieval Poet I», «Anonymous Catalan Medieval Poet II», «Borja, Tecla», «Mallorca, Reina de», «Suaris, Isabel», en K. McNerney y C. Enríquez de Salamanca (eds.), Double Minorities of Spain, New York, Modern Language Association, 1994, pp. 46-47, 79, 211-212 y 364. Un panorama complementario es trazado por Montserrat Cabré, «Medieval Women's Writing in Catalan: Textual Inscriptions of Feminine Authority», La corónica, 32/1 (2003), pp. 23-41.

${ }^{10}$ Según confirmaba la antología de Miguel Ángel Pérez Priego (ed.), Poesía femenina en los cancioneros, Madrid, Castalia, 1989, y Jane Whetnall, «Isabel González of the Cancionero de Baena and Other Lost Voices», La corónica, 21/1 (1992), pp. 59-82.

${ }^{11}$ Remito ahora solo a Mercedes Brea y Pilar Lorenzo Gradín, A cantiga de amigo, Vigo, Xerais, 1998.
} 
recopilados por Garcia de Resende en su Cancioneiro, donde conviven piezas de fines del siglo XV y principios del XVI ${ }^{12}$.

Resulta interesante observar que los estudiosos de las literaturas castellana y gallego-portuguesa medievales han dedicado esfuerzos más notables a la edición y al análisis de estas obras. Las motivaciones que pueden explicar esta constatación serían múltiples: entre ellas no convendría olvidar la importancia de ciertas corrientes de estudio de la literatura popular o la relevancia de las piezas de amigo dentro de la retórica y del imaginario amoroso de los trobeiros. Tampoco convendría olvidar que el descubrimiento de las jarchas de la serie romance en 1948, muchas de ellas con voz femenina ${ }^{13}$ (y la discusión sobre la fecha de nacimiento de la literatura castellana tras los hallazgos posteriores), estimuló por vía complementaria el análisis de una genealogía medieval que, por otra parte, conoció una notable difusión impresa en español durante el siglo XVI, si bien hasta fechas mucho más recientes apenas se prestó atención a la poesía escrita por poetas arábigo-andaluzas ${ }^{14}$. En definitiva, tanto el corpus de lírica catalana compuesto por mujeres como el conjunto de poemas tradicionales con voz femenina en dicha lengua resultan modestos y, probablemente, al no haber favorecido el desarrollo de análisis literarios de mayor calado - caso de las cantigas d'amigo- o de debates filológicos e ideológicos de cierta envergadura -caso de las jarchas-, han sido poco reevaluados. El presente artículo tiene como objetivo ofrecer una aproximación y una reevaluación más generosas al corpus catalán de la lírica popular con voz femenina a partir de las aportaciones más recientes.

\section{El CONTEXTO EN LENGUA CATALANA}

«El estudio de la poesía popular catalana ha sido bastante discreto y nació de la mano de tres de los intelectuales más representativos de la Renaixença catalana del siglo xIx: Pau Piferrer, Manuel Milà i Fontanals y Marià Aguiló i Fuster, que hacia el 1835 comenzaron a recopilar cantos populares» ${ }^{15}$. Este interés prosiguió desde principios del siglo Xx de la mano de folcloristas, historiadores y filólogos o de empresas de largo aliento como la Obra del Cançoner Popular

${ }^{12}$ Tal y como destacara Ana M. Gómez-Bravo, «"A huma senhora que lhe disse”: Sobre la práctica social de la autoría y la noción de texto en el Cancioneiro Geral de Resende y la lírica cancioneril ibérica», La corónica, 32.1 (2003), pp. 43-64.

${ }^{13}$ Cfr. Alan Deyermond, «The Romance kharjas in Hebrew Script: Woman's Song or Man's Text?», en I. Benabu (ed.), Circa 1492. Proceedings of the Jerusalem Colloquium. Litterae Judaeorum in Terra Hispanica (1984), Jerusalem, Hebrew University, 1993, pp. 58-78

${ }^{14}$ Teresa Garulo. «Las poetisas de al-Andalus y el canon de la poesía árabe», La corónica, 32.1 (2003), pp. 65-78.

${ }^{15}$ Josep Lluís Martos, «El género popular de los goigs y Joan Roís de Corella: La vida de la Sacratíssima Verge Maria y la Oració», en C. Alvar et al. (eds.), Lyra Minima Oral. Los géneros breves de la literatura tradicional, Alcalá de Henares, Universidad de Alcalá, 2001, p. 86. 
Català, creada en 1922 y cuyas primeras recopilaciones vieron la luz a partir de 1926. En la actualidad, el punto de partida para el estudio de la lírica tradicional catalana debe ser el Corpus d'antiga poesia popular de Josep Romeu i Figueras (1917-2004), obra fundamental que en el año 2000 fue revisada y ampliada para la colección «Els nostres clàssics» y que alberga un total de 437 piezas de muy variable extensión, compuestas entre los siglos XII al XVI.

No resulta ocioso destacar que el título de esta edición pretendía incidir directamente en la discusión entre hispanistas, romanistas y germanistas sobre el carácter «tradicional»o «popular» de esta poesía. Recordemos ahora que mientras que en el área castellana muchos estudiosos han preferido aplicar el concepto «tradicional», siguiendo las propuestas de Menéndez Pidal, en el ámbito catalán se optó por «popular» desde una época muy temprana ${ }^{16}$. La justificación sobre esta cuestión fue resumida por el propio Romeu en la introducción al volumen de referencia:

l'escola castellana que s'ocupa de la poesia popular ha preferit des de fa molts anys designar aquesta poesia amb la qualificació de tradicional en lloc de popular, al·legant la multiplicitat d'accepcions que té el vocable popular -corrent, conegut, de moda, acceptat pel vulgus, etc. $-i$ sacrificant-ne el sentit primigeni, que no es pot menystenir en favor d'altres accepcions més circumstancials i faltades de contingut específic i propi. La raó del canvi d'apel·latiu respon, segons aquesta escola, al caràcter d'obra transmesa i modificada per successives recreacions que té la poesia popular. Però el mateix podríem dir de la poesia escrita i literària no popular. A més tradicional és un neologisme o un hispanisme usat ja per Milà i Fontanals, al costat del predominant i genuí 'popular'. Tradicionalitat, en aquesta accepció, no inclou plenament el sentit de transmissió oral. A més, no tots els productes populars s'han tradicionalitzat, han sofert l'efecte de la transmissió, perquè no la conegueren o no ens consta: des d'aquest angle, crec que hem de prescindir definitivament de semblant terme ${ }^{17}$.

Se trata de una opción que, en cualquier caso, apenas enturbiaría un ejercicio comparativo, si atendemos los tres planos que propone Romeu para definirla -en relación a la temática, al estilo y a las estructuras formales- y a su funcionalidad predominantemente colectiva. Por extensión, resulta elocuente que Margit Frenk emplease la misma opción que Romeu en su Nuevo corpus de la antigua lírica popular hispánica (siglos XV a XVII), y en las ediciones previas, de

${ }^{16}$ Véanse las propuestas de Vicenç Beltran, «Poesía tradicional / poesía popular», en P. M. Piñero (ed.), De la canción de amor medieval a las soleares. Profesor Manuel Alvar in memoriam, Sevilla, Universidad de Sevilla, 2004, pp. 65-74.

${ }_{17}^{17}$ Josep Romeu i Figueras (ed.), Corpus d'antiga poesia popular, Barcelona, Barcino, 2000, pp. 8-9. 
manera que determinada discusión sobre la nomenclatura se antoja a estas alturas poco productiva, pues en ocasiones más parece apego a una convención o simplemente propicia un ejercicio de historiografía literaria comparada. En todo caso, el concepto «poesía popular» en la escuela catalana se vincula a la creación, mientras que Menéndez Pidal lo aplicaba en términos de su difusión ${ }^{18}$.

A mi juicio, ambos términos se prestan a ciertas confusiones, ya que la crítica de Romeu, sin ir más lejos, admitiría ciertos reparos que afectan directamente el tema del presente artículo. Si aceptamos la dificultad que él mismo constata de hallar una poesía popular medieval en estado puro, mucho más difícil sería admitir la inclusión de un poema como «Gelosesca», del trovador catalán Cerverí de Girona, no tanto porque esté compuesto en lengua occitana -esa sería otra discusión, sobre la que volveré más adelante-, sino porque, siguiendo su nomenclatura, sería un caso evidente de poema «tradicional» (pues imitaría la lírica cantada por el pueblo) y no «popular». Dicho con otras palabras, si aceptáramos la tipología de Romeu -y, con él, de buena parte de los estudiosos de la lírica popular en lengua catalana-, quizá fuera más acertado hablar de «líricas popular y tradicional» y no separarlas en compartimentos estancos, poco fructíferos al menos para la época medieval ${ }^{19}$. Hoy por hoy, no obstante, dada la extensión del uso del adjetivo «popular» en los estudios sobre esta poesía, tanto para el ámbito hispánico como para el catalán ${ }^{20}$, me parece la opción menos equívoca y más acertada.

Las piezas medievales con voz femenina en lengua catalana que ofrece este Corpus d'antiga poesia popular (= CAPP) serían las veinticuatro siguientes:

Ara pren marit, que eu ho vul bé [CAPP 9]

Autoría: Anónima (s. XIII). Estructura: Dístico con rima.

Lassa, mays m'agra valgut [CAPP 35]

Autoría: Anónima (c. 1340). Estructura: Virelai de pie binario ${ }^{21}$.

Més val soleta estar [CAPP 49]

Autoría: Anónima (c. 1350). Estructura: Dístico sin rima.

\footnotetext{
${ }^{18}$ Josep M. Pujol, «Josep Romeu i Figueras, folklorista», en Josep Romeu i Figueras (ed.), Materials $i$ estudis de folklore, Barcelona, Alta Fulla, 1993, pp. 18-22

${ }^{19}$ El propio Romeu reunió algunas de sus investigaciones en un volumen titulado Estudis de lírica popular i lírica tradicional antigues, Barcelona, Abadia de Montserrat, 1993.

${ }^{20}$ Además de los trabajos de Margit Frenk ya citados, véase Mariana Masera, "Que non dormiré sola, non». La voz femenina en la antigua lírica popular hispánica, Barcelona, Azul, 2001.

${ }^{21}$ Para facilitar la lectura, siempre que sea posible se incluirá en nota al pie el enlace de RIALC (Repertorio informatizzato dell'antica letteratura catalana) en donde aparece editada la composición. En el caso de CAPP 35 se correspondería con RIALC 0.70: <http://www.rialc. unina.it/0.70.htm>.
} 


\section{Mala fuy tan fresqueta [CAPP 53]}

Autoría: Anónima (c. 1388). Estructura: Dístico con rima.

\section{Déus, trop se triga qui m'aurà [CAPP 59]}

Autoría: Anónima (ms. finales s. XIV; Libre d'amoretes, primer tercio s. XIV). Estructura: Dístico con rima.

Vejats, son jo assats [...]? [CAPP 60]

Autoría: Anónima (ms. finales s. XIV; Libre d'amoretes, primer tercio s. XIV). Estructura: Dístico con rima.

\section{Perdut, perdut l'è [CAPP 63]}

Autoría: Anónima (ms. finales s. XIV; Libre d'amoretes, primer tercio s. XIV). Estructura: Dístico con rima.

Déus, yo esper d'ell [CAPP 64]

Autoría: Anónima (ms. finales s. XIV; Libre d'amoretes, primer tercio s. XIV). Estructura: Dístico sin rima.

Las, per què nasquí yo anch de mare [...]? [CAPP 66]

Autoría: Anónima (ms. finales s. XIV; Libre d'amoretes, primer tercio s. XIV). Estructura: Dístico sin rima.

Yo he trobat qui m'ama [CAPP 67]

Autoría: Anónima (ms. finales s. XIV; Libre d'amoretes, primer tercio s. XIV). Estructura: No presenta un sistema previsible ni en el metro ni en las rimas.

\section{Ab goyg et alegria [CAPP 74]}

Autoría: Anónima (finales s. XIV). Estructura: Virelai de pie binario. La cuarta estrofa es la única que recoge la voz de la Virgen en su diálogo con el arcángel Gabriel (vv. 29-36) ${ }^{22}$.

Qui leyalment serveix amors [CAPP 79]

Autoría: Anónima (principios s. XV, en Salut d'amor). Estructura: Rondel.

Déus! Car fom tan erguyloses [CAPP 80]

Autoría: Anónima (principios s. XV, en Salut d'amor). Estructura: Rondel.

Pus flach sou que nulha stopa [CAPP 84]

Autoría: Gabriel Ferrús (...1410-1437...). Estructura: Virelai de pie binario ${ }^{23}$.

\footnotetext{
${ }^{22}$ CAPP 74 en RIALC 0bis. Texto completo disponible en $<$ http://www.rialc.unina.it/0bis $\mathrm{ab}$ goig.htm $>$.

${ }^{23}$ CAPP $84=$ RIALC 64.2. Texto completo disponible en $<$ http://www.rialc.unina.it/64.2.htm $>$. 
Anau-vos-en, la mia amor [CAPP 85]

Autoría: Anónima (c. 1428). Estructura: Virelai de pie binario.

Si $\cdot$ trobau al bosch soleta [CAPP 86]

Autoría: Anónima (c. 1429, en la traducción del Decameron). Estructura: Dístico sin rima.

\section{Vitum vitayna [CAPP 89]}

Autoría: Anónima (c. 1429, en la traducción del Decameron). Estructura: Dístico sin rima.

En Burell m'à vist lo cony [CAPP 90]

Autoría: Anónima (c. 1429, en la traducción del Decameron). Estructura: Dístico sin rima.

Ay, marit! Com no m'ho feu [CAPP 92]

Autoría: Anónima (c. 1429, en la traducción del Decameron). Estructura: Forma arcaica: reiteración de una única rima.

No puch dormir soleta, no [CAPP 93]

Autoría: Anónima (c. 1429, en la traducción del Decameron). Estructura: Viadera ${ }^{24}$.

Pus que vuyt jorns stich, senyora [CAPP 94]

Autoría: Anónima (c. 1429, en la traducción del Decameron). Estructura: Viadera ${ }^{25}$.

\section{Dindirindín rindin rindayna [CAPP 101]}

Autoría: Anónima (s. Xv). Estructura: Tirada lírico-narrativa.

La ball, ball, balletes [CAPP 152]

Autoría: Anónima (Cançoneret Rovirola, 1507-1508). Estructura: Tirada lírico-narrativa.

Ou, ou, ou [CAPP 168]

Autoría: Anónima (Cançoneret Rovirola, 1507-1508). Estructura: Trístico con coda. Diálogo entre San José y la Virgen María.

Los resultados de un análisis del conjunto de este Corpus arrojarían los siguientes datos: en primer lugar, la presencia de una voz claramente femenina rondaría el $12 \%$ del total de piezas -apenas una cincuentena- de todo el conjunto, abarcando también, por consiguiente, los manuscritos e impresos del siglo XVI. He tenido en cuenta

\footnotetext{
${ }^{24}$ CAPP 93 = RIALC 0.89. Texto completo disponible en: $<$ http://www.rialc.unina.it/0.89.htm $>$

${ }^{25}$ CAPP 94 = RIALC 0.117. Texto completo disponible en: $<\mathrm{http} / /$ www.rialc.unina.it/0.117. htm>
} 
todos los marcadores genéricos, directos e indirectos, que propician esta atribución -desde los propiamente gramaticales a los contextuales. En segundo lugar, si ciñéramos nuestro análisis a piezas que podemos fechar antes de finales del siglo XV, el corpus quedaría reducido a 24 piezas $(25$, si añadiésemos «Gelosesca», el monólogo de una malmaridada en lengua occitana compuesto por Cerverí de Girona). La segunda mitad de poemas, por consiguiente, aparecería recogida en cancioneros renacentistas -y nada menos que 12 de los cuales en Flor d'enamorats / Flor de enamorados de Joan Timoneda (c. 1556). Las fechas de fijación escrita de estos 24 poemas populares, en tercer lugar, sería: (a) siglo XIII.- 1 poema; (b) siglo XIV.- 10 poemas; (c) siglo XV.- 11 poemas; (d) primera década del siglo XVI.- 2 poemas. En cuarto lugar, la inmensa mayoría son versos anónimos: todos menos uno, el virelai de Gabriel Ferrús compuesto durante el primer tercio del siglo Xv.

Por lo que se refiere a su estructura externa, en quinto lugar, merece la pena destacar que, a pesar de la variedad que puede apreciarse en el corpus, las 24 piezas con voz femenina quedan limitadas a las siguientes modalidades: 14 con formas variables (11 dísticos con o sin rima; 2 tiradas lírico-narrativas; 1 sucesión monorrima) y 10 piezas con estructuras fijas (4 virelais; 2 rondeles; 2 viaderas; 1 trístico con coda; 1 sin estructura clara). La voz femenina no aparece, por consiguiente, en las «noves rimades», los trísticos variables, las coplas de cuatro o de cinco a diez versos, las coplas «laiades» ni en las baladas líricas.

Cabe advertir, en sexto lugar, que de estos 24 poemas medievales, la mitad exacta han sobrevivido gracias a dos obras de muy diversa factura que adquieren especial relevancia: 6 en el Libre d'amoretes, del primer tercio del siglo XIV, y 6 en la traducción catalana del Decamerone (c. 1429) de Giovanni Boccaccio. En este sentido, debe recordarse que los seis dísticos del Libre d'amoretes son otros tantos refranes adaptados de la lengua francesa, de manera que habría que valorar estos versos con especial precaución, pues a pesar de su carácter popular y profano, muy probablemente deban considerarse simples versiones del anónimo traductor sin trascendencia popular real, como el propio Romeu señaló en un artículo ${ }^{26}$. Por tanto, de eliminar estos 6 dísticos, nos quedarían un total de 18 piezas. La operación del traductor del Decamerone fue opuesta, ya que sustituyó los poemas

${ }^{26}$ «Quina incidència tingueren aquests dotze refrains en concret, sigui en llur totalitat $\mathrm{o}$ alguns d'ells, en la nostra poesia popular antiga? Probablement que cap, ans degueren restar confinats dins les pàgines del llibre, en llur mera funció estilística i metafòrica. Traduïts i tot, no degueren transcendir a l'aire lliure, ni transmetre's pel cant, ni difondre's per tradició. Bé que molt interessants i exemplars d'un aspecte curiós de transmissió poètica, resten reduïts a testimoniatges de poesia popular forana traduïts a la nostra llengua i encastats en una bella obreta literària de bona acceptació a casa nostra durant un moment cultural força precís, de marcat influx francès i que molt bé por correspondre al temps de Joan I» (Romeu i Figueras, Estudis, op. cit., p. 132). 
italianos que aparecen cantados al final de diversas jornadas por versos originales en lengua catalana, probablemente conocidos por sus lectores al tratarse de piezas que remiten a canciones de danza ${ }^{27}$.

Por último, en lo que atañe al plano del contenido, puede confirmarse que la temática amorosa es la predominante, aunque con matices diversos. Así, están presentes las malcasadas (CAPP 9 y 94) y las malmonjadas (35 y 53), la auto-alabanza (60), la felicidad (67, 79 y 101) y el erotismo más o menos velado $(86,89,90$ y 92$)$, aunque predominen las piezas sobre la separación o la ausencia del amado $(59,63,64,66,85$ y 93$)$.

\section{Piezas COMPlementarias}

A estas veinticuatro piezas quizá debieran añadirse otras cuatro, tres de las cuales nos llegan por vías complementarias, aunque su entidad sea diversa. La primera sería la pastorela «Ay, espigua novela», editada en 2001 por Gemma Avenoza, en cuyos versos 21-28 participa una joven requerida de amores. Se trata de una pieza descubierta con posterioridad a la publicación del Corpus y que podría valorarse dentro de este proyecto, pues Romeu incluyó diversas composiciones tardías vinculadas a este subgénero lírico-narrativo, que sobre todo alcanzó difusión en círculos cortesanos: «La poesia pastoral, versió cortesana $i$ sublimació de la rusticitat $i$ la puresa càndida $i$ clàssica dels personatges d'ègloga, també hi és representada per uns quants exemples tardans, que proven que el subgènere no s'adoptà a la nostra poesia fins a la segona meitat del segle XVI» (11). Serían ocho versos hexasílabos con una estructura de dansa ${ }^{28}$.

La segunda pieza a la que me refiero nos llega a través de un canal completamente diverso y su entidad misma resulta bien diferente: se trata de la propuesta de Rafael Beltrán de reconstrucción de un fragmento narrativo del Tirant lo Blanch en clave de poema popular con voz femenina ${ }^{29}$. Éste sería el caso de los versos disfrazados -al ser transformados en prosa por Joanot Martorell- que pronuncia la doncella Eliseu durante el episodio en el que se narran los amores entre la emperatriz de Constantinopla y el joven Hipòlit (capítulos 248-264): se trata de una oración, pero, de nuevo, no convendría descartarla,

${ }^{27}$ «Les set peces catalanes pertanyien sens dubte a cançons de dansa, i devien ésser refranys de peces dansades més extenses [...] Totes aquestes petites peces constitueixen, en definitiva, un testimoniatge molt valuós de poesia popular, tradicional i folklòrica de la Catalunya de la segona meitat del segle XIV i primers anys del XV» (Romeu i Figueras, ibid., pp. 160-161).

${ }^{28}$ «Ay, espigua novela» en RIALC 0bis. Texto completo en $<$ http://www.rialc.unina. it/0bis.ay_espigua.htm>. Gemma Avenoza, «Ai espiga novela! Estudi i edició d'una pastorel·la catalana del s. XIV», en L. Funes y J. L. Moure (eds.), Studia in honorem Germán Orduna, Alcalá de Henares, Universidad de Alcalá, 2001, pp. 53-71.

${ }^{29}$ Rafael Beltrán, «Huellas de las oraciones de Los tres reyes de Oriente y Las cuatro esquinas en Tirant lo Blanc», en C. Alvar et al. (eds.), Lyra Minima Oral. Los géneros breves de la literatura tradicional, Alcalá de Henares, Universidad de Alcalá, 2001, pp. 415-424. 
teniendo en cuenta que Romeu introdujo en su Corpus un buen número de oraciones, conjuros y ensalmos, con frecuencia vinculados al espacio doméstico femenino: «Finalment, com una síntesi de profanitat i devoció intuïtiva trobem els conjurs i les oracions destinats a la prevenció de perills i a la curació de malures. Formen un gènere ben definit en el qual la incongruència en tots sentits, la desbordada fantasia i la llibertat per dir l'inefable de la màgia ho són tot» (10). La «versificación» de Beltrán ofrecería el siguiente resultado:

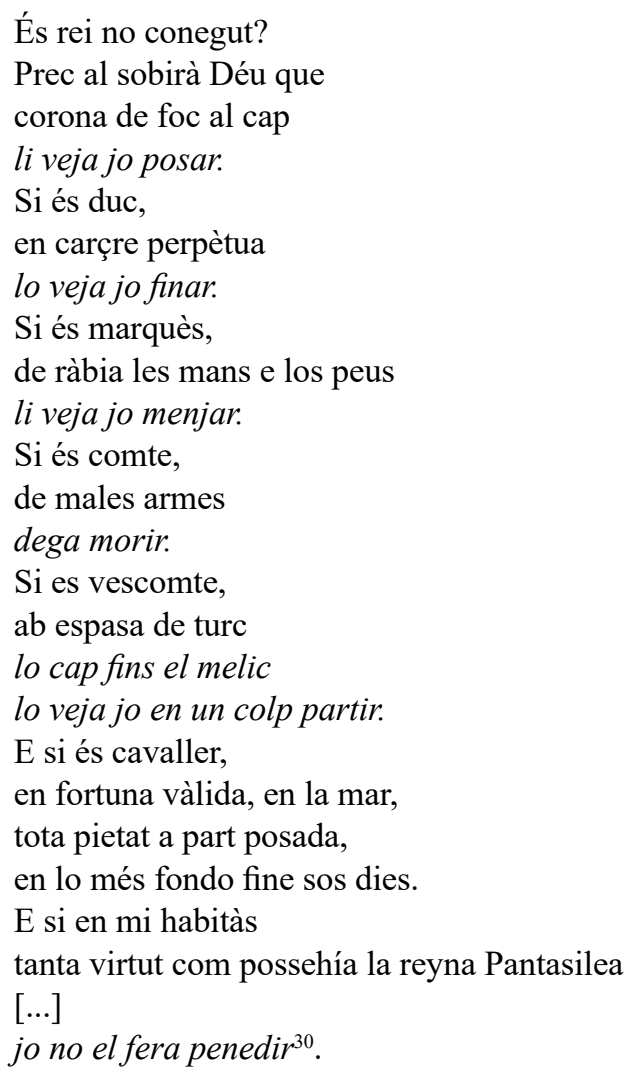

Ya he señalado que Josep Romeu i Figueras incluyó en su Corpus d'antiga poesia popular la Gelosesca, del trovador Cerverí de

${ }^{30}$ La versión española de J. F. Vidal Jové de este fragmento del capítulo 262 de la novela es la siguiente: «¿Es un rey desconocido? Ruego a Dios soberano, que yo le vea poner corona de fuego en la cabeza. Si es duque, que le vea acabar sus días en cárcel perpetua. Si es marqués, de rabia las manos y los pies le vea yo comer. Si es conde, de malas armas deba morir. Si es vizconde, con espada de turco la cabeza hasta el ombligo le vea partir. Y si en mí hubiese tanta virtud como poseyera la reina Pantasilea, de su atrevimiento yo le haría arrepentir» (Martorell Galba 736), Joanot Martorell y Martí Joan de Galba. Tirant lo Blanc, Joan Francesc Vidal Jové (trad.), Madrid, Alianza, 1984. Albert Hauf edita el texto original en parte como una oración (Martorell 980-81). Joanot Martorell, Tirant lo Blanch, Albert Hauf (ed.), València, Tirant lo Blanch, 2005. 
Girona ( 1259-1285 ), canción de malcasada contra el marido celoso. Se trata de la composición «tradicional» más temprana con voz femenina de todo el volumen: Al fals gelós don Déu mala ventura es un virelai en lengua occitana de pie binario, formado por tres estrofas unissonans y una vuelta, que, dada la relevancia de su autor ha conocido numerosas ediciones (CAPP 7) ${ }^{31}$. Esta incorporación, tan indiscutible desde múltiples perspectivas, empezando por el conocido factor de que la lengua poética más extendida y cultivada en las cortes de la Corona de Aragón durante los siglos XII al XIV fue la occitana-hecho que favorece que las composiciones iniciales del Corpus sean versos de Guillem de Berguedà (núms. 1-3: «Cansoneta leu e plana...», "Cantarey mentre m'estau...» y «Chansson ai comensada...») y Cerverí de Girona (núms. 4-7: Ayçò és viadeyra, Peguesca, Espingadura y Gelosesca)-, me permite abrir un último paréntesis para reflexionar en torno a una cuestión que no debiera desdeñarse: el plurilingüismo en las tierras catalanas medievales.

Y es que, a mi juicio, si aceptáramos la inclusión de esta canción en lengua occitana del trovador catalán, de manera que, en cierta medida, rompiésemos el criterio estrictamente lingüístico de las veintiséis piezas anteriores, tal vez conviniese incorporar al proyecto de estudio de la lírica popular con voz femenina catalana, o tal vez mejor en tierras catalanas, al menos un poema más, a la zaga de la propuesta de Martí de Riquer, quien lo incorporaba en su Antologia de poetes catalans (núm. 54, 182-183) ${ }^{32}$. Se trata de una poesía festiva de tono y temática claramente popular en forma de diálogo entre una joven y su viejo esposo durante la noche de bodas, compuesta entre 1340 y 1420, editada y traducida por Jaume Riera i Sans ${ }^{33}$ en Cants de noces dels jueus catalans (9 y 16-21), donde recopila las cinco únicas composiciones conservadas en grafía hebrea pero con vocablos catalanes; es decir, con una transmisión aljamiada. Las estrofas segunda y cuarta, con voz femenina, remiten a la perfección a la tradición de la malcasada románica que expresaba sus cuitas en la

${ }^{31}$ Una traducción sencilla de esta pieza sería: «(1-3) Al falso celoso, dé Dios mala ventura, ya que me quita todo el solaz de mi amigo, y me enferma desde que lo tuve, pues tanto me dura. (4-10) Pero estoy muy segura de que no vivirá cuatro días el falso celoso malvado, esto os digo, ya que le pondré sobre el pulso tal untura que le matará. Me ha hecho un buen talismán mi dulce amigo, que bajo el cuello le ligo, y mi madre siempre lo conjura. (11-17) ¿Sabéis qué me hace el celoso de fea figura cuando se va a la cama? Sólo decirlo siento asco: me gira la espalda, que tiene negra y dura, y más áspera que hoja de roble; después ronca y silba sin medida. Espero vestirme de luto pronto, pues nunca había visto criatura más desagradable. (18-24) Lejos está del gozo, cerca está de la tristeza y del disgusto quien tiene marido pesado, falso y malvado: bien lo sé, para desventura mía, que me dieron los míos como amigo un viejo arrugado, quien con su sudor me daña y me ablanda. Quien le vea, si quiere ahorrarse un mal pesar, que le diga que Dios le dé buena pastura. (25-27) La señora de los Cardos y la de Sobreprecio tienen valor y el Infante tiene poder de sobras para mantener mérito, paz y justicia».

${ }^{32}$ Martín de Riquer (ed.), Antologia de poetes catalans. Un mil-leni de literatura, I. Ėpoca medieval, Barcelona, Galaxia Gutenberg, 1997.

${ }^{33}$ Jaume Riera i Sans (ed.), Cants de noces dels jueus catalans, Barcelona, Llibres del Mall, 1974. 
Gelosesca de Cerverí de Girona y en tantas otras piezas de la lírica popular catalana e hispánica:

La ne'arà li·n diu: «Perdut n'haveu el moah!

No n'haveu virtut ne punt de koah!

Tot lo vostre feit és un bel ruah!

Mas io prec en Déu que en breu ne sia almanà».

[...]

La ne'arà li·n diu: «Feu-me aquel ma'as'e!

Par que n'hajau (dolor) al gid ha-nasé.

Més per Déu i la Llei de Moisès us ben juro

que si vós no me'l feu io esquinçaré la ketuhà» ${ }^{34}$.

El estudio de la lírica popular catalana constituye un desafío por múltiples razones, algunas de las cuales he ido apuntando a lo largo de este trabajo, en parte como consecuencia de las dimensiones y características del corpus conservado. En este sentido, el análisis de la presencia de las voces femeninas puede propiciar reflexiones de muy diverso calado, no solo relacionada con cuestiones vinculadas a su autoría o a la representación de los roles de género, sino, además, a la acotación misma de las tipologías textuales, culturales y lingüísticas en que floreció durante centurias.

Recibido: $19 / 05 / 2017$

Aceptado: 25/06/2018

${ }^{34}$ Una modesta traducción de estas estrofas sería: «La chica le dice: “¡Habéis perdido el juicio! ¡No tenéis virtud ni nada de fuerza! ¡Todo vuestro hacer es un bello pedo! Pero rezo a Dios para que pronto sea viuda”. [...] La chica le dice: “¡Hacedme aquel acto! Parece que tengáis dolor en el tendón. Mas os juro por Dios y por la Ley de Moisés que si vos no me lo hacéis, romperé los papeles"». 
$\cos$

\section{EL CORPUS MEDIEVAL DE LA LÍRICA POPULAR CATALANA CON VOZ FEMENINA}

RESUMEN: El presente trabajo tiene como objetivo analizar la presencia de la voz femenina en el corpus de la lírica popular catalana de la Edad Media. Con tal propósito, y tras presentar los resultados de las líneas de investigación principales en el área románica, se estudiará el Corpus d'antiga poesia popular de Josep Romeu i Figueras y serán comentadas las características temáticas y formales de este conjunto formado por veinticuatro poemas. Por último, se propone la inclusión de tres piezas adicionales, de origen diverso, que nos permitirán reflexionar sobre cuestiones relacionadas con sus tipologías textuales, culturales y lingüísticas.

PAlabras Clave: Lírica catalana de la Edad Media, Poesía tradicional europea, La mujer en la literatura catalana medieval, Estudios de género, Josep Romeu i Figueras.

\section{FEMALE VOICES IN CATALAN TRADITIONAL POETRY FROM THE MIDDLE AGES}

ABSTRACT: The goal of this essay is the analysis of female voices in Catalan traditional poetry from the Middle Ages. After introducing the main achievements of previous research in Romance literatures, we will study Josep Romeu i Figueras' Corpus d'antiga poesia popular as well as the formal and thematic traits of the extant group of 24 poems. Last, the article suggests to include 3 more texts, whose presence will offer the opportunity to think about some issues related to textual, cultural and linguistic typologies.

Keywords: Medieval Catalan Poetry, European Traditional Poetry, Women in Medieval Catalan Literature, Genre Studies, Josep Romeu i Figueras. 